\title{
Knowledge, Attitude and Practiceon Prevention of Iron Deficiency Anemia Among Pregnant Women Attending Ante Natal Care Unitat Public Hospitals of Harar Town, Eastern Ethiopia
}

\author{
Masresha Leta Serbesa ${ }^{1}$, Maleda Tefera Iffa ${ }^{2}$ \\ ${ }^{1}$ Department of Midwifery, Harar Health Science College, Harar, Ethiopia \\ ${ }^{2}$ Department of Nursing, Haramaya University, Harar, Ethiopia \\ Email address: \\ masreshaleta3@gmail.com (M. L. Serbesa),maledaifa.21@gmail.com (M. T. Iffa) \\ To cite this article: \\ Masresha Leta Serbesa, Maleda Tefera Iffa. Knowledge, Attitude and Practiceon Prevention of Iron Deficiency Anemia Among Pregnant \\ Women Attending Ante Natal Care Unitat Public Hospitals of Harar Town, Eastern Ethiopia. American Journal of Health Research. \\ Vol. 7, No. 3, 2019, pp. 38-45. doi: 10.11648/j.ajhr.20190703.12
}

Received: February 21, 2019; Accepted: May 17, 2019; Published: July 31, 2019

\begin{abstract}
Background: Globally, the most common cause of anemia is iron deficiency, which is responsible for about half of anemia cases in pregnancy, and it is estimated that in developed countries $38 \%$ of pregnant women have iron depletion. In developing countries, the major causes of anemia in pregnancy are nutritional deficiencies, parasitic infestations, HIV infection, hemorrhage and some chronic medical disorders like renal and hepatic diseases. Recent statistics indicate that anemia affects $57 \%$ of pregnant women globally with the highest prevalence in sub-Saharan Africa. Anemia is an indicator of nutritional deficiencies that significantly contribute to birth defects, preterm labour and low birth weight, hence it causes global public health problem. Objectives:- To assess knowledge, attitude and practice on prevention of Iron deficiency anemia among pregnant women attending ante-natal care unit at public Hospitals of Harar town, eastern Ethiopia from March, 12 - April 06, 2018. Method:- The study was done in Harar town on the public hospitals from March 12-April 12, 2018. The study design was institutional based cross sectional study. By using a single population formula \& by making a correction formula our sample size was 128 , which the pregnant women was select by simple random sampling from each Hospitals after proportional allocated based on the total sample size. The data was collected using close ended semi-structured questioners by trained 4 diploma nurses with 1 supervisor. For processing \& analyzing SPSS version 20 was used \& the data were presented by table, graph \& chart using frequency \& percentage of the results. Discussion: In our study the prevalence anemia shows $32 \%$ which indicate less than study done in Azerbaijan, Kazakhstan, Uzbekistan, Kyrgyz, Egypt, Jordan, higher than Armenia \& Moldova this may due to sample size \& study area difference. Similar study in Sierra Leone among the 185 subjects, majority (89.2\%) had heard about anemia. Which is comparable to our study, $68.1 \%$ recognized lack of iron in food as the cause for anemia, which is low in our study. About $69.7 \%$ pointed that consuming iron rich foods could prevent anemia, in our study it is less. Conclusion: according to our study the prevalence of IDA were low, this may related to most had knew, had positive attitude and practice method use to prevent iron deficiency anemia.
\end{abstract}

Keywords: Knowledge, Attitude, Practice, Anemia

\section{Introduction}

A balanced amount of nutrients in food is need for all human being regarding to proper body system functions. This indicates that Nutrition is a fundamental pillar for the human being, for the health \& development of entire life [1]. Now a days for both developed \& developing country malnutrition is the great problem, which in developed country the obesity a major problem \& related chronic non communicable diseases were occurred but, In developing countries, while widespread under-nutrition and micronutrient deficiencies persist. [2] 
During Pregnancy Proper dietary balance is necessary to ensure sufficient energy intake for adequate growth of fetus without drawing on mother's own tissues to maintain her pregnancy [3]

Pregnancy is also a period of a significant increase in iron requirement; the demand is higher due to physiological changes in maternal red blood cell mass and also due to the needs of the development and growing of the placenta and fetus. Despite increased iron requirements, pregnancy is also a period of increased risk for anemia which is higher than in non-pregnant state [4-6]

According to WHO definition of Anemia is "a condition in which the number of red blood cells (RBCs) or their oxygencarrying capacity is inadequate to meet physiologic demands in the body, in which the hemoglobin level may vary by age, sex, altitude, smoking, and pregnancy status"

Anemia in pregnancy is identified by the WHO as hemoglobin level less than $11 \mathrm{~g} / \mathrm{dl}$ and is divided into three levels of severity, Mild anemia ( $\mathrm{Hb}$ level, 9-10.9g/dl), Moderate anemia ( $\mathrm{Hb}$ level, 7-8.9g/dl) and severe anemia (Hb level 7-4.5 g/dl). [7]

In sub-Saharan Africa, there are multiple causes of anemia in pregnancy, which include inadequate diet, iron folate and vitamin B12 deficiencies, impaired micronutrient absorption, blood loss resulting from hemorrhage, and helminthes infestation. [8]

In Ethiopia $27 \%$ of women are undernourished with a body mass index (BMI) of less than the 18.5 cutoff point and only $4 \%$ are obese with a BMI of more than 25.0. The major problems are protein-energy malnutrition and micronutrient deficiencies such as vitamin A, iron, and iodine. These figures put Ethiopia among sub-Saharan countries with the highest proportion of malnourished women. [9]

Anemia affects over two billion people globally, among whom over 40 million are pregnant women, where iron deficiency is thought to be the most common cause of anemia and its account for $75 \%-95 \%$ of cases. [10]

Recent statistics indicated that anemia affects $57 \%$ of pregnant women globally with the highest prevalence in subSaharan Africa. [11]

Anemia is an indicator of nutritional deficiencies that significantly contribute to birth defects, preterm labour and low birth weight, hence it causes global public health problem. However, iron deficiency anemia is a leading cause of maternal morbidity and mortality, prenatal and prenatal infant loss; physical and cognitive losses thus in developing countries stall social and economic development. In subSaharan countries the magnitude of anemia in pregnancy is quite alarming, whereby its prevalence is widely contributed by poor nutrition, iron and other micronutrients deficiencies, parasitic infestations, chronic infections, illiteracy, and short pregnancy intervals. [12]

Women with iron deficiency anemia may be asymptomatic, however is more susceptible to infection, may tire easily, with increased chance of preeclampsia and postpartum hemorrhage, and tolerates poorly even minimal blood loss during birth. Healing of an episiotomy or an incision usually delayed and if the anemia is severe (Hb less than $6 \mathrm{~g} / \mathrm{dL}$ ), cardiac failure may ensue. On the other hand, there was evidence of increased risk of low birth weight (Low birth weight/ less than $2.500 \mathrm{~g}$ ). Iron deficiency anemia is associated with a higher incidence of low-birth weight infant's preterm birth, pre-maturity, stillbirth, and neonatal death in infants of women with severe iron deficiency (maternal $\mathrm{Hb}$ less than $6 \mathrm{~g} / \mathrm{dL}$ ). [13]

The prevalence of anemia in Ethiopian among women of $15-49$ age group is $17 \%$, southeast Ethiopia is $27.9 \%$ (38) Lack of awareness is the major retarding factor to reach millennium development goal, as the awareness of anemia among pregnant women is only $72 \%$. Anemia was found to be severe public health problem in Ethiopia that is greater than $40 \%$ of pregnant women were anemic. [14]

Iron deficiency and other micronutrients are the main cause of anemia throughout the world and it's common in women of reproductive age where these deficiencies may lead to birth defects, preterm labour, low birth weight and resulting in an increase in prenatal death. [15]

Many women suffer from a combination of chronic energy deficiency, poor weight gain in pregnancy, anemia, and other micronutrient deficiencies, as well as infections like HIV and malaria. These along with inadequate obstetric care, contribute to high rates of maternal mortality and poor birth outcomes. [16]

Despite anemia having been identified as a global public health problem for several years, no rapid progress has been observed, and the prevalence of the disease is still high globally. [17] Despite interventions of treating and preventing maternal anemia, still many pregnant women are affected by anemia related health problems and the contributing factors for the persistence of high incidences are not empirically known. [18] Far reduction and control of anemia prevalence among women remains prioritized as a public health problem. [5] Therefore, the aim of the study was to assess the current status of anemia and assess the knowledge, attitude \& practice of prevention of Iron deficiency anemia among pregnant women in Harar town at public Hospitals who came to ANC follow up. This study was also able to identify the Knowledge, attitude \& practice of pregnant women on prevention of nutritional anemia in Harar town, which showed how far the problem was exit \& what measurement should be taken. Also different health institution including health centers was used as a baseline data to work on such type of gap related to their institutional capacity \& care.

\section{Method and Material}

Institutional based cross sectional study design was employed from March 12 - April 06, 2018 among 128 pregnant women attending ANC clinic at public hospitals of Harar town Eastern Ethiopia. The study was conducted in Harari region, which was located in the eastern part of Ethiopia between latitude of $90^{\circ}$ north and longitude of $42^{\circ}$ east. The total population distribution of Harari region 
(urban and rural) is 250,903 out of this the urban population is 139,200 or $60 \%$, in rural area the population is 92,800 or $40 \%$. population in sex distribution males accounts about 116,928 and females are115,072. 31,482 of the Harari population are under 5 children and the dependent group accounts 135,579 and the reproductive age groups are about 64,939 .

The required sample size was determined by using single proportion formula. The required sample size was computed based on the three objectives, which are Knowledge, attitude and practice. So, according to our sampling size determination by comparing the three sample size of the objectives P1, P2 \& P3 the larger sample size was 372 then by adding $10 \%$ of non-respondent rate, total sample size were 409. But, the average monthly flowing of pregnant women in both Hospitals of our study area were 186, so using correction formula we adjust the sample size to be 128 .

Data was collected using structured close ended questioners, the questioners includes socio-demographic part, knowledge related, attitude related \& practice related on prevention of IDA among pregnant women again the questioners were prepared by English version and translated to local language. The data was collected using 4 diploma clinical nurses \& supervised by $1 \mathrm{BSc}$ clinical nurse. But, before data collection the data collector \& supervisor were trained for 1 day, the questioners were adopted form different literatures. Data quality was assured through $10 \%$ data was pre-tested at Federal police Hospital of Harar town which was out of our study area.

The results was presented in the form of tables, figures and text using frequencies and summary statistics such as mean, mode, standard deviation and percentage to describe the study population in relation to relevant variables

In order to confirm the ethical and legal standard of the investigator, approval was obtained from the ethical review board of Harar Health Science college. The survey was commence after written consent obtained from Jugal and Hiwot fana specialized university hospitals and consent obtained from the study participants.

\section{Result}

\subsection{Socio-Demographic Characteristics of the Participants}

From the total of 128 participants majority, 39(30.5\%) found under age category of 23-27, 38(29.7\%) were 18-22 years, $33(25.7 \%) \&$ the least $2(1.6 \%)$ were $38-42$, On marital status majority, $107(83.6 \%)$ were married \& the least $3(2.3 \%)$ were single \& widowed, On their education status majority 50(39.1\%) were diploma \& above and secondary school and remains 28(21.9\%) were learned primary education, Employment status showed majority were $59(46.1 \%)$ working in governmental institution, remain $34(26.6 \%), 22(17.2 \%), 13(10.2 \%)$ were private worker, farmer \& housewife respectively, in other way majority $78(60.9 \%)$ had 2 family members, remain $43(33.6 \%) \&$
$7(5.5 \%)$ had $3 \&$ above 3 respectively, majority 59(46.1\%) of respondents were have $>2500$ birr monthly income and $27(21.1 \%)$ had $1000-1500$ birr and most $106(82.8 \%)$ of were live in city.

Table 1. Shows socio-demographic data of the participants on knowledge, attitude and practice on prevention of iron deficiency anemia among pregnant women attending ante-natal care unit at public hospitals of Harar town, eastern Ethiopia, March, 12 - April 06, 2018.

\begin{tabular}{|c|c|c|}
\hline Variables & Frequency & Percentage \\
\hline \multicolumn{3}{|l|}{ Age categories } \\
\hline $18-22$ & 38 & 29.7 \\
\hline $23-27$ & 39 & 30.5 \\
\hline $28-32$ & 33 & 25.7 \\
\hline $33-37$ & 13 & 10.2 \\
\hline $38-42$ & 2 & 1.6 \\
\hline $43-47$ & 3 & 2.3 \\
\hline \multicolumn{3}{|l|}{ Marital status } \\
\hline Single & 3 & 2.3 \\
\hline Married & 107 & 83.6 \\
\hline Divorced & 15 & 11.7 \\
\hline Widowed & 3 & 2.3 \\
\hline \multicolumn{3}{|l|}{ Educational Status } \\
\hline Primary school & 28 & 21.9 \\
\hline Secondary school & 50 & 39.1 \\
\hline Diploma \& above & 50 & 39.1 \\
\hline \multicolumn{3}{|l|}{ Employment status } \\
\hline Farmer & 13 & 10.2 \\
\hline Governmental & 59 & 46.1 \\
\hline Private & 34 & 26.6 \\
\hline House wife & 22 & 17.2 \\
\hline \multicolumn{3}{|l|}{ Number of family } \\
\hline 2 & 78 & 60.9 \\
\hline 3 & 43 & 33.6 \\
\hline$>3$ & 7 & 5.5 \\
\hline \multicolumn{3}{|c|}{ Family monthly income } \\
\hline $1000-1500$ & 27 & 21.1 \\
\hline $1500-2500$ & 42 & 32.8 \\
\hline$>2500$ & 59 & 46.1 \\
\hline \multicolumn{3}{|l|}{ Leaving area } \\
\hline City & 106 & 82.8 \\
\hline Rural & 22 & 17.2 \\
\hline
\end{tabular}

\subsection{Maternal Related Response of the Study Participants}

From total $\mathrm{N}=128$ of respondents, majority $65(50.8 \%)$ were married at age between 16-20, others 33(25.8\%) \& $26(20.3 \%)$ married at the age intervals of $21-25 \& 26-30$ respectively. Most $65(50.8 \%)$ gave birth 1 st at the age of 18-22 years, also $22(16.4 \%)$ were at age of $28-32$ years gaves their 1 st birth, majority $66(51.6 \%)$ of participants had pregnant for the 1 st time and remain $42(32.8 \%)$, $18(14.1 \%)$ were pregnant for 2 nd\& 3 rd time respectively, majority $103(80.5 \%)$ of the respondents were not suffered from health related problem \& Most 60(46.9\%) were visited for the $1 \mathrm{st}$ time in the health institution, but $43(33.6 \%) \& 25(19.5 \%)$ were visited for the 2 nd\& 3 rd time respectively. 
Table 2. Shows maternal related data of the participants on knowledge, attitude and practice on prevention of iron deficiency anemia among pregnant women attending ante-natal care unit at public hospitals of Harar town, eastern Ethiopia, March, 12 - April 06, 2018.

\begin{tabular}{lcl}
\hline Variables & Frequency & Percentage \\
\hline Age at first marriage & & \\
$16-20$ & 65 & 50.8 \\
$21-25$ & 33 & 25.8 \\
$26-30$ & 26 & 20.3 \\
$>=31$ & 4 & 3.1 \\
Age of $~^{\text {st }}$ pregnancy & & \\
$18-22$ & 65 & 50.8 \\
$23-27$ & 41 & 32 \\
$28-32$ & 22 & 16.4 \\
$>=33$ & 1 & 0.8 \\
Number of pregnancy & & \\
1 & 66 & 51.6 \\
2 & 42 & 32.8 \\
3 & 18 & 14.1 \\
4 & 2 & 1.6 \\
Years of child spacing & & \\
$<3$ Years & 51 & 39.8 \\
$3-4$ Years & 11 & 8.6 \\
No have child before & 66 & 51.6 \\
Stage of pregnancy & & \\
$1^{\text {st }}$ trimester & 50 & 39.1 \\
$2^{\text {nd }}$ trimester & 50 & 39.1 \\
$3^{\text {rd }}$ trimester & 28 & 21.9 \\
Do you suffering from health problem & \\
Yes & 25 & 19.5 \\
No & 103 & 80.5 \\
Number visit to the health institution & 60 \\
$1^{\text {st }}$ time & 43 & 19.5 \\
$2^{\text {nd }}$ time & 25 & \\
$3^{\text {rd }}$ time & & \\
\hline & & \\
\hline
\end{tabular}

\subsection{Knowledge of Pregnant Mothers on Prevention of Iron Deficiency Anemia}

From the total $\mathrm{N}=128$ participants that were asked for knowledge related to iron deficiency anemia, majority $113(88.3 \%)$ have heard about IDA, which there source were $71(55.5 \%), 16(12.5 \%), 12(9.4 \%), 14(10.9 \%)$ health care workers, radio, printed materials \& other related like friends or neighbor respectively but, $15(11.7 \%)$ were not heard about IDA at all.

Among definition of anemia 40(31.3\%), 33(25.8\%) \& $7(5.5 \%)$ defines anemia is iron deficiency, poor nutrition \& low hemoglobin respectively, related to this from these participants majority $18(14.1 \%), 15(11.7 \%), 14(10.9 \%)$ were respond general body weakness, dizziness or fainting, poor appetite \& shortness of breathing are sign\& symptom of anemia but, remain $48(37.5 \%)$ were not known the definition appropriately, on cause of anemia majority $45(35.2 \%)$ were know poor nutrition is cause for anemia, also 26(20.3\%), $3(2.3 \%), 6(4.7 \%)$, were aware bleeding during pregnancy, Multiple pregnancy and spacing \& all listed may take as cause for anemia but, remain $48(37.5 \% 0$ didn't know the cause for anemia.

On knowledge related to prevention of anemia, majority
$75(58.6 \%)$ knows how anemia can be prevent from these pregnant mothers they know anemia can be prevent $40(31.3 \%), 25(19.5 \%), 7(5.5 \%)$ by good or healthy nutrition, using iron supplement \& drinking or eating fruits respectively but, 53(41.4\%) didn't know how anemia can be prevented, majority 89(69.5\%) didn't know drinking coffee, tea \& milk can reduce iron absorption, 78(60.9\%) were aware that child spacing can reduce anemia, which $68(53.1 \%) \& 10(7.8 \%)$ aware that spacing child between 2 year and above $\&<2$ years respectively but 50(39.1\%) were have no awareness about this at all.

Table 3. Shows knowledge of the participants on knowledge, attitude and practice on prevention of iron deficiency anemia among pregnant women attending ante-natal care unit at public hospitals of Harar town, eastern Ethiopia, March, 12 - April 06, 2018.

\begin{tabular}{|c|c|c|}
\hline Variables & Frequency & Percentage \\
\hline \multicolumn{3}{|c|}{ Have heard about iron deficiency anemia? } \\
\hline yes & 113 & 88.3 \\
\hline no & 15 & 11.7 \\
\hline \multicolumn{3}{|l|}{ Source of information $1^{\text {st }}$} \\
\hline Health care worker & 71 & 55.5 \\
\hline Radio & 16 & 12.5 \\
\hline Printed materials & 12 & 9.4 \\
\hline Others & 14 & 10.9 \\
\hline Not heard & 15 & 11.7 \\
\hline \multicolumn{3}{|l|}{ What is anemia? } \\
\hline Poor nutrition & 33 & 25.8 \\
\hline Iron deficiency & 40 & 31.3 \\
\hline Low hemoglobin & 7 & 5.5 \\
\hline I don't know & 48 & 37.5 \\
\hline \multicolumn{3}{|l|}{ Sign \& symptom of anemia } \\
\hline shortness of breathing & 14 & 10.9 \\
\hline Exceptional fatigue & 12 & 9.4 \\
\hline General body weakness & 18 & 14.1 \\
\hline Poor appetite & 15 & 11.7 \\
\hline Dizziness or fainting & 18 & 14.1 \\
\hline All can be observed & 3 & 2.3 \\
\hline I don't know & 48 & 37.5 \\
\hline \multicolumn{3}{|l|}{ Cause of anemia } \\
\hline Poor nutrition & 45 & 35.2 \\
\hline Bleeding during pregnancy & 26 & 20.3 \\
\hline Multiple pregnancy \& spacing & 3 & 2.3 \\
\hline All listed above & 6 & 4.7 \\
\hline I don't know & 48 & 37.5 \\
\hline \multicolumn{3}{|c|}{ Do you know how to prevent anemia? } \\
\hline Yes & 75 & 58.6 \\
\hline No & 53 & 41.4 \\
\hline \multicolumn{3}{|l|}{ How can we prevent anemia? } \\
\hline By good nutrition & 40 & 31.3 \\
\hline Using Iron supplement & 25 & 19.5 \\
\hline Drinking or Eating fruits & 7 & 5.5 \\
\hline All listed above & 3 & 2.3 \\
\hline I don't know & 53 & 41.4 \\
\hline \multicolumn{3}{|c|}{$\begin{array}{l}\text { Do you know drinking tea, coffee } \& \text { milk can reduce iron absorption in the } \\
\text { body? }\end{array}$} \\
\hline Yes & 39 & 30.5 \\
\hline No & 89 & 69.5 \\
\hline \multicolumn{3}{|c|}{ Do You know spacing child can prevent anemia? } \\
\hline Yes & 78 & 60.9 \\
\hline No & 50 & 39.1 \\
\hline \multicolumn{3}{|c|}{ Which one is best spacing of child to prevent anemia? } \\
\hline$<2$ years & 10 & 7.8 \\
\hline 2 years $\&$ above & 68 & 53.1 \\
\hline I don't know & 50 & 39.1 \\
\hline
\end{tabular}




\subsection{Attitude of Pregnant Mothers on Prevention of Iron Deficiency Anemia}

From total $\mathrm{N}=128$ participants majority $52(40.6 \%) \&$ $53(41.4 \%)$ were strongly agree \& agree respectively on regular visit have benefit both for the mother \& fetus health during pregnancy but, $17(13.3 \% \%)$ did not know benefit of this, related to effect iron supplement to the mother \& fetus $45(35.2 \%) \& 35(27.3 \%)$ were agree \& strongly agree but, $47(36.7 \%)$ don't know about the benefit, related to drinking of tea, coffee \& milk can reduce iron absorption majority $70(54.7 \%)$ were not know this, but 37(28.9\%), 11(8.6\%), $10(7.8 \%)$ were agree, strongly agree \& disagree on the idea respectively, on Iron supplement or iron tablets can prevent anemia 50(39.1\%) \& 21(16.4\%) were agreed \& strongly agree but, 52(40.6\%) didn't know supplement or tablet of iron can prevent anemia.

Related to feeding regular meal to prevent anemia majority $64(50 \%)$ agree but, $48(37.5 \%)$ didn't know, related to Pregnant women should consume Iron tablets in spite of healthy diet $46(35.9 \%) \& 15(11.7 \%)$ were agreed \& strongly agreed but, 53(41.4\%) didn't know at all, related to family planning on prevention of anemia majority $60(46.9 \%)$ were agreed again 54(42.2\%) were didn't know this, on child spacing on preventing of anemia $54(42.2 \%)$ were agreed in approximately $51(39.8 \%)$ didn't know at all and lastly on pregnancy to expose for anemia $53(41.4 \%) \& 13(10.2 \%)$ were agreed \& strongly agreed but, 49(38.3\%) didn't know pregnancy to expose for anemia.

Table 4. Shows attitude of the participants on knowledge, attitude and practice on prevention of iron deficiency anemia among pregnant women attending ante-natal care unit at public hospitals of Harar town, eastern Ethiopia, March, 12 - April 06, 2018.

\begin{tabular}{|c|c|c|}
\hline Variables & Frequency & Percentage \\
\hline \multicolumn{3}{|c|}{$\begin{array}{l}\text { Do you believe that regular visit use to health of mother \& fetus during } \\
\text { pregnancy? }\end{array}$} \\
\hline Strongly disagree & 5 & 3.9 \\
\hline Disagree & 1 & .8 \\
\hline Agree & 53 & 41.4 \\
\hline Strongly agree & 52 & 40.6 \\
\hline I don't know & 17 & 13.3 \\
\hline \multicolumn{3}{|c|}{ Iron supplement can affect mother \& fetus health? } \\
\hline Strongly disagree & 1 & .8 \\
\hline Agree & 45 & 35.2 \\
\hline Strongly agree & 35 & 27.3 \\
\hline I don't know & 47 & 36.7 \\
\hline \multicolumn{3}{|c|}{ Drinking coffee, tea or milk can affect iron absorption } \\
\hline Disagree & 10 & 7.8 \\
\hline Agree & 37 & 28.9 \\
\hline Strongly agree & 11 & 8.6 \\
\hline I don't know & 70 & 54.7 \\
\hline \multicolumn{3}{|c|}{ Iron supplement or iron tablets can prevent anemia } \\
\hline Strongly disagree & 3 & 2.3 \\
\hline Disagree & 2 & 1.6 \\
\hline Agree & 50 & 39.1 \\
\hline Strongly agree & 21 & 16.4 \\
\hline I don't know & 52 & 40.6 \\
\hline \multicolumn{3}{|c|}{ Regular meals or feeding can prevent anemia } \\
\hline Strongly disagree & 1 & .8 \\
\hline Disagree & 2 & 1.6 \\
\hline Agree & 64 & 50.0 \\
\hline
\end{tabular}

\begin{tabular}{lcc}
\hline Variables & Frequency & Percentage \\
\hline Strongly agree & 13 & 10.2 \\
I don't know & 48 & 37.5 \\
Pregnant women should consume Iron tablets in spite of healthy diet \\
Strongly disagree & 4 & 3.1 \\
Disagree & 10 & 7.8 \\
Agree & 46 & 35.9 \\
Strongly agree & 15 & 11.7 \\
I don't know & 53 & 41.4 \\
Promotion of family planning methods for spacing with prevent anemia \\
Strongly disagree & 1 & .8 \\
Disagree & 2 & 1.6 \\
Agree & 60 & 46.9 \\
Strongly agree & 11 & 8.6 \\
I don't know & 54 & 42.2 \\
Spacing child can prevent anemia & & \\
Strongly disagree & 8 & 6.3 \\
Disagree & & \\
Agree & 54 & 42.2 \\
Strongly agree & 15 & 11.7 \\
I don't know & 51 & 39.8 \\
Any pregnant women can be affected by anemia & \\
Strongly disagree & 4 & 3.1 \\
Disagree & 9 & 7.0 \\
Agree & 53 & 41.4 \\
Strongly agree & 13 & 10.2 \\
I don't know & 49 & 38.3 \\
\hline
\end{tabular}

\subsection{Practice of Pregnant Mothers on Prevention of Iron Deficiency Anemia}

From total $\mathrm{N}=128$ of pregnant mothers majority $68(53.1 \%)$ were not drink tea, coffee \& milk with their meal but, $60(46.9 \%)$ practiced it, related to using of regular iron tablet $87(68 \%)$ were not used but $41(32 \%)$ were used still, majority $76(59.4 \%)$ were feed following 3 regular meals, remain $52(40.6 \%)$ not feed regular meal, related to taking of Folic acid supplements in current pregnancy, majority 76(59.4\%) were use currently but, 52(40.6\%) did not use this supplement.

On other hand 62(48.4\%), 72(56.3\%) \& 75(58.6\%) were have the habit of Eating red meat, liver, chicken, fish, eggs, legumes, fruits, include fiber rich food frequently\& include green leafy vegetable in their diet every day respectively but, 66(51.6\%), 56(43.8\%) \& 53(41.4\%) were have no habit of feeding this types of food at all. Again according to their level of hemoglobin $87(68 \%)$ of pregnant mothers were had hemoglobin level $>=11 \mathrm{mg} / \mathrm{dl} \&$ the rest $41(32 \%)$ have $<11 \mathrm{mg} / \mathrm{dl}$.

Table 5. Shows Practice of the participants on knowledge, attitude and practice on prevention of iron deficiency anemia among pregnant women attending ante-natal care unit at public hospitals of Harar town, eastern Ethiopia, March 12 - April 06, 2018.

\begin{tabular}{lll}
\hline Variables & Frequency & Percentage \\
\hline Have you drink tea, coffee \& milk with meal? & & \\
Yes & 60 & 46.9 \\
No & 68 & 53.1 \\
Have you used regular iron Tablets? & & \\
Yes & 41 & 32.0 \\
No & 87 & 68.0 \\
Have you use three regular meals? & & \\
Yes & 76 & 59.4 \\
No & 52 & 40.6 \\
\hline
\end{tabular}




\begin{tabular}{lcc}
\hline Variables & Frequency & Percentage \\
\hline Have you taken Folic acid supplements in current pregnancy? & 76 & 59.4 \\
Yes & 52 & 40.6 \\
No & 62 & 48.4 \\
Do you have the habit of Eating red meat, liver, chicken, fish & \\
Yes & 66 & 51.6 \\
No & & \\
Do you include fiber rich food frequently? & 72 & 56.3 \\
Yes & 56 & 43.8 \\
No & 75 & 58.6 \\
Do you include green leafy vegetable in your diet every day? & \\
Yes & 53 & 41.4 \\
No & & \\
Hemoglobin level & 41 & 32 \\
$<11 \mathrm{mg} / \mathrm{dl}$ & 87 & 68 \\
$>=11 \mathrm{mg} / \mathrm{dl}$ & & \\
\hline
\end{tabular}

\section{Discussion}

In our study the prevalence anemia shows $32 \%$ which indicate less than study done in Azerbaijan, Kazakhstan, Uzbekistan, Kyrgyz, Egypt, Jordan, higher than Armenia \& Moldova this may due to sample size $\&$ study area difference.

A study done on Nabulus, Palestine a higher prevalence rate of IDA was found among city inhabitance 35 out of 137 $(25.5 \%)$, Younger age group $(\leq 24)$ in the study seems to show the highest prevalence similarly in our study the city inhabitants had higher prevalence this may related to city inhabitants are more exposed to this types of diseases

According to our study on awareness related to cause of anemia most had knew poor nutrition, bleeding during pregnancy \& multiple pregnancy as cause for IDA, similar study done in Palestine on 162 participants, Inadequate nutrition included not having a balanced diet containing protein-rich foods, not consuming iron-rich foods such as fish, chicken, beef, pork, beans and not consuming iron supplements or treating malaria to cause IDA this may due the cause for IDA is not difference for any type of pregnant mothers, Fifty-six participants stated, "don't know" as a response, but in our study it low this may due to study area difference \& difference on sample size.

Another study in Palestine $\mathrm{N}=171$, A majority of participants know (53\%) correctly identify preventive and treatment options for anemia. Examples of these preventive measures were eating nutritionally sufficient diets and protein rich foods were considered for anemia treatment and prevention, also indicated intake of iron supplements and multivitamins as preventive and treatment options, this was higher in our this may due to sample size difference.

A study done in Tanzania shows generally, the respondents with secondary education $(38 \%)$ and those of higher level of education had higher level of knowledge and awareness on anemia.

Sixty-one percent of participants $(n=106)$ erroneously provided information about anemia prevention and treatments such as providing references to having sound sleep, resting, and not over thinking, A few participants did not know how to prevent or treat anemia $(n=30,17 \%)$

The study done on Sierra Leone on 2012 shows $99 \%$ had heard about anemia \& as source of information on anemia the majority of participants indicated that they could get information about anemia from medical settings, but this is less in our study this may difference on information dissemination of the country or difference on study area

Similar study in Sierra Leone among the 185 subjects, majority (89.2\%) had heard about anemia. Which is comparable to our study, majority of them (68.1\%) recognized lack of iron in food as the cause for anemia, which is low in our study. About 69.7 percent pointed out that consuming iron rich foods could prevent anemia, which is less than our study, but most of them (53\%) did not know about the food items that inhibited iron absorption, this was high in our study this my due to difference on study area \& sample size difference.

High level of knowledge was reported in Palestine by IDA group of the participants with regard to the definition of anemia as $64.7 \%, 67.6 \%$ and $88.2 \%$ were able to link anemia with poor nutrition, iron deficiency and low $\mathrm{Hb}$ levels, respectively, in our study a this link had observed but it is lower than Palestine due to sample size \& awareness on IDA difference.

Knowledge concerning symptoms associated with IDA was also found to be at high level and this is evident from the finding of $88.9 \%, 84.5 \%, 93.3 \%, 75.6 \%$ and $80 \%$ of the participants reported that IDA is associated with the following symptoms fatigue, general weakness, dizziness and fainting, headaches and pallor of face, lips and nail beds, respectively, according to our study participants knew all sign \& symptoms seen on IDA mother this is due to most of sign \& symptom of anemia diseases is relate with this.

According to our study most the participants knew shortness of breathing, weakness, poor appetite, dizziness, fainting as sign \& symptom of anemia, this was similar to study done in Palestine unless their difference on their frequency \& percentage due to sample size difference

Palestine study on 2007, A highly positive attitude was also found with respect to the daily use of iron supplements during pregnancy and as recommended by the specialists. This was clear from the findings among IDA group (97.8\%) approve the use of iron supplements, comparably in our study most of participants agree \& strongly agree on family planning \& consuming of iron tablets, this may due to both of them had awareness on prevention of IDA by using iron tablets \& family planning.

Study done at 2007 in Palestine, A positive attitude towards disapproval of multiple pregnancies was reported by (97.7\%; IDA). Positive attitude towards the use of family planning methods was also found among these study groups (73.3\%; IDA), in our study similarly most of pregnant mothers were had positive attitude related to family planning $\&$ prevention of IDA but, low in frequency \& percentage this may difference due to sample size and study area.

Study on 400 pregnant women admitted to one of the hospital In Romania in 2010, showed that $45.3 \%$ of participants had used iron supplements during pregnancy, which is higher in our study, In another Findings from cross- 
sectional analysis of data collected from 836 participants at Porto, Portugal, 2008, reported that Prevalence of use of supplements during pregnancy was $55.4 \%$ for folic acid, which is comparable with our study, this may due to sample size difference \& different study area.

The prevalence of women who took iron tablets and syrup during their most recent pregnancy was $44 \%$ in 2012 in the Kyrgyz Republic, which is higher in our study this may due to difference on study area $\&$ habit of using.

A study done at west Ethiopia as the current study reported that, only $31.5 \%$ of participants would not drink tea or coffee with meal, but in our this was high this may due to sample size, while $71 \%$ of them took iron supplements with fruits juices at least sometimes, which less in our study this may due to different on using habits, $62.9 \%$ of participants use iron supplements regularly while, Similar study at rural area of India on 50 antenatal mothers showed that iron folate tablet was adequately consumed by $62 \%$ mothers among the study population. $79.4 \%$ of participants have had regular three times meal per day, this is higher in our study $59.4 \%$ use folic acid which lower \& 59.4\% were feed regular three times feeding also lower than the other this may due to sample size difference.

\section{Conclusion}

According to our study $32 \%$ of pregnant mothers were with IDA (Hg level of $<11 \mathrm{mg} / \mathrm{dl}$ ) which is lower than others study, this may most of pregnant mothers had knowledge on cause \& prevention of anemia, they had also positive attitude for most of preventing method of IDA like on implementation of family planning \& on supplement of iron folate for pregnant mothers, again practically most of pregnant mothers took supplement of folic acid in their current pregnancy, had habit to feed types of food rich in iron $\&$ which increase absorption iron.

\section{Recommendation}

According to our study most of pregnant mothers were non-IDA, $32 \%$ were with IDA so, there are more jobs to be done to decrease this prevalence, the following activities are recommended on decreasing of IDA by increasing the knowledge, attitude \& skill towards prevention of IDA, which are:-

-Strengthening Health Education on Anemia Prevention during ANC follow up and preparations of brochure which describes symptoms, risks factors and ways of IDA preventions and increase the positive perception of pregnant mothers towards on prevention of IDA.

-Involving private health facilities in support of societal awareness towards prevention of IDA during pregnancy.

-All study area surrounding health facilities and offices should work on strengthening the awareness, perception \& utilization on preventive methods of IDA during pregnancy. Including or participating husbands of pregnant mothers on the practice which are done to prevent IDA.

\section{List of Acronyms and Abbreviation}

ANC: Antenatal Care, BMI: Body Mass Index, g/dL: Gram per deciliter, Hb: Hemoglobin, HIV: Human Immunodeficiency Virus, IDA: Iron Deficiency Anemia, WHO: World Health Organization

\section{Availability of Data and Materials}

This is a research article

\section{Competing Interests}

We declare that we have no competing interests.

\section{Acknowledgements}

We would like to extend appreciations to individuals who involved in data collection and Hiwot fana and jugal hospital staffs who willingly gave us all the information we needed without any reservation.

\section{Authors' Contribution}

ML and MT, conceived the study, participated in the design, data analysis and interpretation of the result. ML involved in data acquisition, writing the draft manuscript as well as making all the changes as suggested by the coauthors. MT critically reviewed the manuscript. All authors read and approved the manuscript.

\section{References}

[1] Daba G BF, Fekadu H, Garoma W. Assessment of Knowledge of Pregnant Mothers on Maternal Nutrition and Associated Factors in Guto Gida Woreda, East Wollega Zone, Ethiopia. J Nutr Food Sci. 2013; 3.

[2] Shekar M HR, Lee Y-K.. Repositioning nutrition as central to development:. World Bank Publications. 2006.

[3] Subarnalata S PB. a study of nutritional status of pregnant women of some villages in Balasore district, Orissa. J Hum Ecol. 2006; 20: 227-32.

[4] Dim C, Jennifer, Z. and Onah, H. Prevalence of anaemia among pregnant women at Booking in Enugu, South Eastern Nigeria. Medscape General Medicine Journal. 2007; 9: 11-81.

[5] Noronha JA, Khasawneh, E. A., Raman, S. and Seshan, V. Anemia in pregnancy and challenges. Journal of South Asian Federation of Obstetrics and Gynaecology. 2012; 4: 64-70.

[6] Tay KCS, Agboli, E. and Walana, W. Malaria and anemia in pregnant and non pregnant women of child-bearing age at the University Hospital, Kumasi, Ghana. Open Journal of Medical Microbiology. 2013; 3: 193-200.

[7] WHO. Micronutrient deficiencies: Iron deficiency anemia. 2012. 
[8] Olubukola $\mathrm{AaO}$, A. Anaemia in pregnancy at two level of health care in Ibadan South west Nigeria. Department of obstetrics and gynecology Medical Statistics and Environmental Health. 2011; 10: 272-7.

[9] Literature Review Prepared for the Message and Materials Development Workshop produced through support provided by the United States Agency for International Development (USAID) AA, Ethiopia. IYCN. Infant \& Young Child Nutrition Project. 2011.

[10] Osungbade $\mathrm{KOaO}$, A. O. Preventive treatments of iron deficiency anemia in pregnancy. Journal of Pregnancy. 2012.

[11] Abriha A, Yesuf, E. M. and Wassie, M. M., University of Gonador. Ethiopia 7:, 2014. Prevalenceand associated factors of anaemia among pregnant women of Mekelle Town, Ethiopia. American Journal of health SCi. 2014; 7: 1756-888.

[12] Okeke UP. Anaemia in pregnancy it is a persisting public health problem in Porto Novo Capeverde. Journal of Medical Sciences. 2011; 5: 193-9.
[13] Salzberg HS. Nutrition in pregnancy. In J. J Sciarra (Ed.), Gynecology and obstetrics. Philadelphia: Lippincott Williams \& Wilkins. 2002.

[14] Ethiopia mini demographic and health survey Central statistical agency AA, Ethiopia 2014: 41-53.

[15] Karaoglu L, Pehlivan, E., Gunes, G. and Egri, M. Prevalence of nutritional anemia in pregnancy in East Anatolian Province, Turkey. Journal of Public Health. 2010; 10: 1471-2458.

[16] Huffman S ZE, Harvey P, Martin L, Piwoz E, et al. Essential Health Sector Actions to Improve Maternal Nutrition in Africa. 2001.

[17] Ghislain KaM, M. Prevalence and risk factors in a malariaendemic Area in Benin. The American Society of Tropical Medicine and Hygiene. 2012; 87: 418-24.

[18] M. Ja. prevalence, knowledge and attitude of pregnant women on control measures of anaemia in mbulu district, tanzania. 2015. 